\title{
Effect of bumetanide on toluene diisocyanate induced contractions in guinea pig airways
}

\author{
Cristina E Mapp, Anna Boniotti, Alberto Papi, Carlo A Maggi, Antonino Di Stefano, \\ Marina Saetta, Adalberto Ciaccia, Leonardo M Fabbri
}

\begin{abstract}
Background The loop diuretic frusemide has been shown to inhibit the bronchoconstrictor response to exercise, inhaled allergen, distilled water, adenosine, and sodium metabisulphite. Toluene diisocyanate contracts smooth muscle by activating capsaicin sensitive nerves and causes asthma that shares many features with allergen induced asthma.
\end{abstract}

Methods The study was designed to assess the effect of two loop diuretics, bumetanide $(10$ and $100 \mu M)$ and frusemide $(100 \mu \mathrm{M})$, on smooth muscle contraction induced by toluene diisocyanate $(0.03-1000 \mu \mathrm{M})$ in guinea pig airways with and, in the case of bumetanide, without epithelium. The effect of bumetanide on the response to acetylcholine, neurokinin $A$, and electrical field stimulation in guinea pig bronchial smooth muscle rings was also examined. Results Bumetanide (10 and $100 \mu \mathrm{M}$ ) had no effect on toluene diisocyanate induced contraction whether airway epithelium was present or not. Frusemide $(100 \mu M)$ caused no significant inhibition of toluene diisocyanate induced contraction (mean reduction on the entire curve $25 \%$ ). Bumetanide inhibited non-adrenergic, non-cholinergic contraction induced by electrical field stimulation of bronchi pretreated with atropine $(1 \mu M)$ and indomethacin $(5 \mu M)$ and this inhibition was inversely related to the frequency of stimulation, suggesting that bumetanide may be inhibiting transmitter release at the prejunctional level. Bumetanide and frusemide did not inhibit the responses to exogeneous acetylcholine $(0 \cdot 1 \mu M)$ or neurokinin $A$ (1 nM).

Conclusions Bumetanide and frusemide in doses that are known to inhibit nonadrenergic, non-cholinergic contraction due to electrical field stimulation failed to inhibit the response to toluene diisocyanate in guinea pig airways.

(Thorax 1993;48:63-67)

Bumetanide and frusemide are high ceiling diuretics and both inhibit the $\mathrm{Na} / \mathrm{K} / \mathrm{Cl}$ cotransporter in renal tubules. Bumetanide is more potent than frusemide but the two compounds have a similar effect on $\mathrm{Na} / \mathrm{K} / \mathrm{Cl}$ cotransport in various mammalian tissues. ${ }^{12}$

Frusemide, when administered by nebuliser but not orally, has been shown to protect asthmatic patients against non-specific and specific bronchoconstrictor stimuli. ${ }^{3-8}$ The mechanism of action of frusemide in vivo has not been determined. Because frusemide but not bumetanide inhibits adenosine 5'-monophosphate and sodium metabisuphite induced bronchoconstriction in asthmatic persons, it was recently suggested that the protective effect of frusemide may be independent of the $\mathrm{Na} / \mathrm{K} /$ $\mathrm{Cl}$ cotransport. ${ }^{9}$ The effect of high ceiling diuretics such as frusemide and bumetanide could be due to inhibition of the $\mathrm{Na} / \mathrm{K} / \mathrm{Cl}$ cotransport in airway smooth muscle, thus reducing contractility, ${ }^{10}$ or it could be due to inhibition of chloride secretion into the bronchial lumen by blocking $\mathrm{Na} / \mathrm{Cl}$ cotransport on the basolateral membrane of epithelial cells. ${ }^{11} 12$ Other possible mechanisms include inhibition of epithelial cell swelling and oedema induced by osmotic stimuli, ${ }^{13}$ inhibition of mediator release from inflammatory cells, ${ }^{14}{ }^{15}$ and an effect on the responsiveness of sensory nerves. ${ }^{16}$

There is evidence to suggest that loop diuretics inhibit both cholinergic and excitatory non-adrenergic, non-cholinergic neurotransmission in guinea pig airways ${ }^{17}$ without a direct effect on airways smooth muscle. This effect may be due to inhibition of the $\mathrm{Na} / \mathrm{K} / \mathrm{Cl}$ cotransport. As we have shown that toluene diisocyanate contracts smooth muscle by activating capsaicin sensitive sensory nerves $^{18-20}$ we have studied the effects of bumetanide and frusemide on the contraction of guinea pigs airway smooth muscle in vitro induced by toluene diisocyanate. Toluene diisocyanate, a widely used industrial chemical, is a potent airway sensitiser and able to induce occupational asthma. ${ }^{21}$ We also examined the effects of bumetanide on airway smooth muscle contraction in guinea pig bronchial rings in vitro induced by acetylcholine, neurokinin A, and electrical field stimulation.

\section{Methods}

PREPARATION OF TISSUE

The experimental procedure and specific protocols were approved by the committee on animal care of the University of Padova.

Male Hartley outbred guinea pigs (Rodentia Laboratories, Torre Pallavicina, Bergamo) weighing $300-400 \mathrm{~g}$ were anaesthetised with pentobarbital sodium $(50 \mathrm{mg} / \mathrm{kg}$ intraperitoneally). The lungs were removed rapidly and immersed in oxygenated Krebs-Henseleit solution containing $118.3 \mathrm{mmol} / \mathrm{l} \mathrm{NaCl}$, 
$4.7 \mathrm{mmol} / 1 \quad \mathrm{KCl}, \quad 1.2 \mathrm{mmol} / \mathrm{l} \quad \mathrm{MgSO}_{4}$, $1.2 \mathrm{mmol} / 1 \mathrm{KH}_{2} \mathrm{PO}_{4}, 25.0 \mathrm{mmol} / 1 \mathrm{NaHCO}_{3}$, $2.5 \mathrm{mmol} / 1 \mathrm{CaCl}_{2}$, and $11.1 \mathrm{mmol} / 1 \mathrm{D}(+)-$ glucose). The main bronchi were dissected free of loose connective tissue and were prepared in two rings. The rings were mounted in glass chambers filled with $15 \mathrm{ml}$ of Krebs-Henseleit solution that was maintained at $37^{\circ} \mathrm{C}$ and gassed with a mixture of $95 \% \mathrm{O}_{2}$ and $5 \% \mathrm{CO}_{2}$, which produced a $\mathrm{pH}$ of $7 \cdot 4$. The bronchial rings were connected to force displacement transducers (Grass FTO3) for continuous recording of isometric tension. The rings were allowed to equilibrate for 90 minutes while resting tension was adjusted to $5 \mathrm{mN}$. During equilibration the medium was changed every 20 minutes. Contractions were expressed as a percentage of the active tension obtained in response to acetylcholine $(1 \mathrm{mM})$. Bronchial rings dissected free of epithelial and connective tissue and bronchial rings with intact epithelium were studied. The epithelium was removed by rubbing the luminal surface gently with gauze, cut into strips, and tied at one side to a suture; this was used to guide the gauze inside the bronchial rings. Removal of the epithelium was confirmed histologically. At the end of the experiment control rings and rings without epithelium were fixed in $4 \%$ formaldehyde in $0 \cdot 1 \mathrm{M}$ phosphate buffer at $\mathrm{pH} 7 \cdot 2$. After fixation, samples were dehydrated with ethanol, passed through xylene, and embedded in paraffin. Sections $6 \mu \mathrm{m}$ thick were cut perpendicular to the minor internal diameter of the bronchi and tissue blocks were oriented for light microscopical analysis. Four sections at intervals of $100 \mu \mathrm{m}$ were stained with haematoxylin in eosin. The sections were coded and examined without knowledge of the physiological data. Light microscopical (Jenamed 30G0040) measurements were obtained with an eyepiece graticule at a magnification of 160 . The length of the mucosa without epithelium was measured and expressed as a percentage of the total length of basement membrane in the section. The final result is the mean of all the measurements performed in each specimen.

DRUGS

Acetylcholine and frusemide were obtained from Sigma Chemical Co (St Louis, MO, USA) and neurokinin A from Peninsula (St Helens, England). Bumetanide was given by Dr F Gaetani (Sigma-Tau).

Toluene diisocyanate consisted of an $80: 20$ mixture of the 2,4 and 2,6 isomers and was obtained from Montedison (Porto Marghera, VE, Italy). It was dissolved in dimethyl sulphoxide and prepared fresh before each study. The maximum final concentration of dimethyl sulphoxide in the organ bath was $0.3 \%$. Bumetanide was dissolved in $100 \%$ ethanol. A stock solution of frusemide was made up in $10 \mathrm{mM}$ sodium hydroxide solution and diluted with distilled water to the appropriate concentration. Addition of the solutions used to dissolve the drugs was shown to have no effect on resting tension.

\section{EXPERIMENTAL PROTOCOLS}

Toluene diisocyanate

The effect of bumetanide and frusemide on the airway response to increasing concentrations of toluene diisocyanate $(0.03-1000 \mathrm{mM})$ was assessed. After an equilibration period a baseline response to acetylcholine was obtained. The rings were then rinsed. Parallel experiments were carried out on paired bronchial rings from the same animal; bumetanide (10 $\mu \mathrm{M}$ or $100 \mu \mathrm{M}$, contact time 30 minutes) or frusemide (100 $\mu \mathrm{M}$, contact time 30 minutes) was added to one of the two bronchial rings of each animal and nothing was added to the second ring. The response to increasing concentrations of toluene diisocyanate was then measured in both rings. Each successive concentration of toluene diisocyanate was added only after the previous response had reached a constant value. The effect of bumetanide was studied on rings with and without epithelium; the effect of frusemide was studied on rings with epithelium.

Neurokinin A, acetylcholine, and electrical field stimulation

The effect of bumetanide $(10 \mu \mathrm{M})$ on the responses to neurokinin $A$, acetylcholine $(0 \cdot 1 \mu \mathrm{M})$, and electrical field stimulation was also examined. In these experiments atropine $(1 \mu \mathrm{M})$ was added to antagonise the cholinergic component of the response to electrical field stimulation and indomethacin $(5 \mu \mathrm{M})$ to minimise the spontaneous variations in tone of the tissue. Under these conditions a reproducible contractile response to electrical field stimulation was obtained for several hours. Experiments started after a 90 minute equilibration period. The preparations underwent field stimulation $(1-10 \mathrm{~Hz}, 60 \mathrm{~V}, 0.5 \mathrm{~ms}$ for $10 \mathrm{~s})$ by means of two wire platinum electrodes placed at the top and the bottom of the organ bath and connected to a Grass $\$ 11$ stimulator. A frequency-response study $(1-10 \mathrm{~Hz})$ was carried out on the bronchial rings without epithelium until a reproducible response was obtained. Ethanol (the solvent for bumetanide) or bumetanide $(10 \mu \mathrm{M})$ was added to the bath and a further frequency-response curve was carried out 30 minutes later. The response was expressed as a percentage of the maximal contraction obtained with $40 \mathrm{mM} \mathrm{KCl}$.

\section{ANALYSIS}

Values are given as mean (SE). The effects of bumetanide and frusemide on contraction induced by toluene diisocyanate and of bumetanide on contraction induced by acetylcholine, neurokinin A, and electrical field stimulation were compared by two tailed Student's $t$ test for paired data and by analysis of variance (ANOVA) with repeated measures (BMDP Statistical Software, Inc, Los Angeles, CA). Values of $p<0.05$ were considered significant.

\section{Results}

TOLUENE DIISOCYANATE

Toluene diisocyanate caused a concentration 
dependent contraction of bronchial smooth muscle in bronchi with epithelium. Bumetanide (10 and $100 \mu \mathrm{M}$ ) did not alter the toluene diisocyanate induced contractions (fig 1).

Toluene diisocyanate also caused contraction in bronchial rings without epithelium, and this did not differ significantly between control rings and rings pretreated with bumetanide (10 and $100 \mu \mathrm{M}$; fig 2). Histological analysis confirmed that $94 \cdot 1(4 \cdot 6) \%$ of the epithelium had been removed.

Frusemide $(100 \mu \mathrm{M})$ did not alter toluene diisocyanate induced contraction significantly (fig 3). At a concentration of $300 \mu \mathrm{M}$ of toluene diisocyanate there was a $39 \%$ reduction in rings pretreated with frusemide $(95 \%$ confidence interval ( $95 \%$ CI) $78 \%-14 \%$ of response to $1 \mathrm{mM}$ acetylcholine). The mean values found in control rings and in frusemide treated rings were $64.5(14.3) \%(95 \%$ CI $97 \%-32 \%$ of the response to $1 \mathrm{mM}$ acetylcholine) and 39.1 (6.7)\% (95\% CI $54 \%-24 \%$ of the response to $1 \mathrm{mM}$ acetylcholine) respectively. The table gives the results for both drugs.

\section{ACETYLCHOLINE AND NEUROKININ A}

Bumetanide (10 $\mu \mathrm{M}$, contact time 30 minutes) did not alter the response to $0 \cdot 1 \mu \mathrm{M}$ acetylcholine. The contractions were $43.6(4.8) \%$ in control rings and $45.0(8.8) \%$ in bumetanide treated rings ( $n=6, N S$ ).

Bumetanide pretreatment (10 $\mu \mathrm{M}$, contact time 30 minutes) did not alter the response to $1 \mathrm{nM}$ neurokinin A. Contractions were 23.4 $(2 \cdot 8) \%$ in control rings and $22.8(4 \cdot 2) \%$ in bumetanide treated rings $(n=6, N S)$.

Frusemide $(100 \mu \mathrm{M}$, contact time $30 \mathrm{~min}$ utes) did not alter the response to $0 \cdot 1 \mu \mathrm{M}$

Figure 1 Effect of toluene diisocyanate on guinea pig main bronchi with epithelium intact in the absence (open circles) and presence (closed circles) of bumetanide $(10 \mu M$ panel $A ; 100 \mu M$ panel $B$ ). Each point is the mean (SE) of six experiments. Ach-acetylcholine.

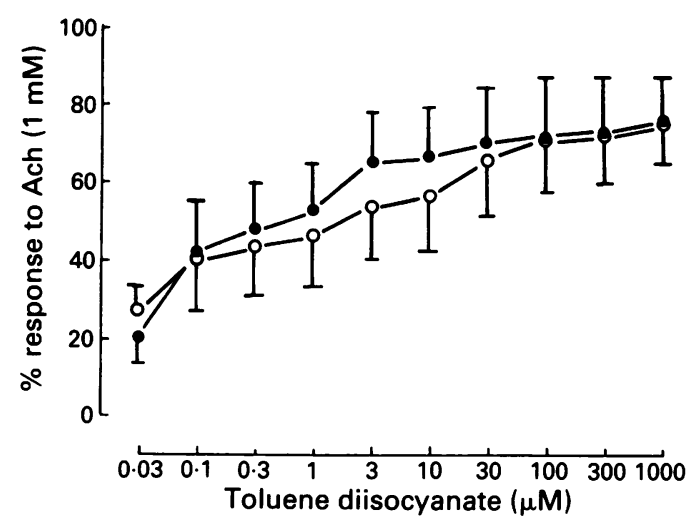

A

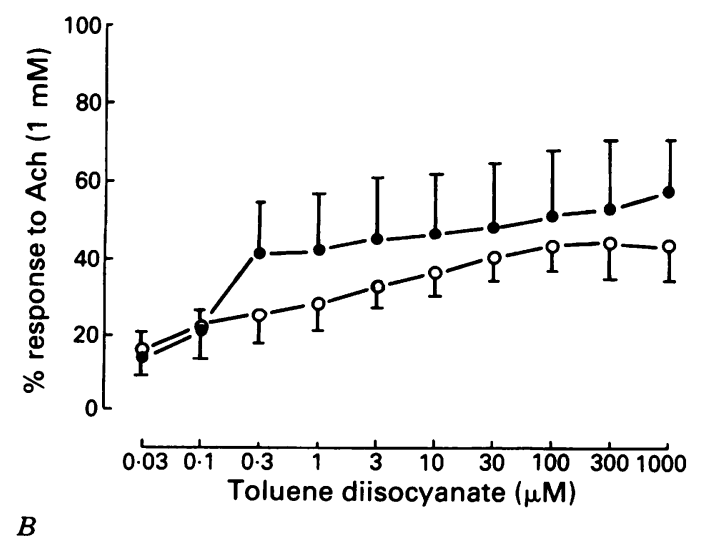

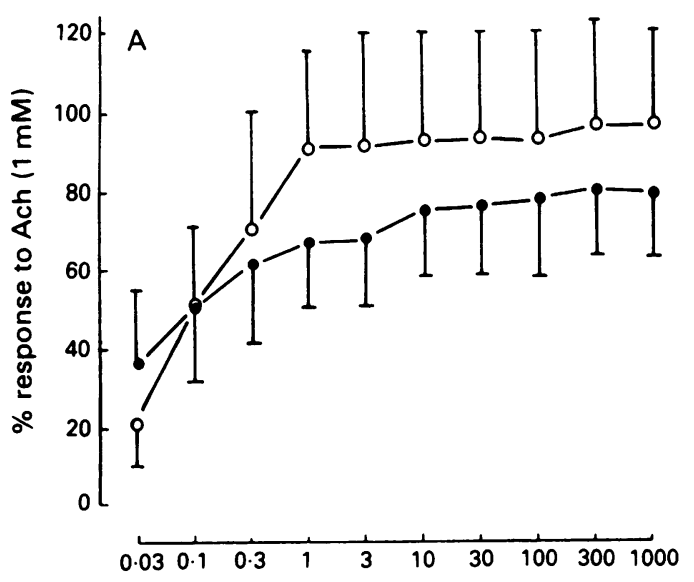

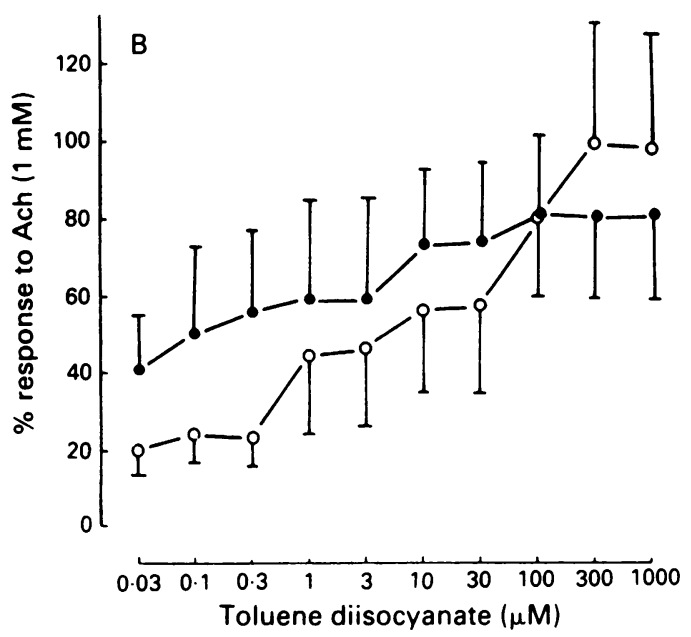

Figure 2 Effect of toluene diisocyanate on guinea pig main bronchi with the epithelium removed in the absence (open circles) and presence (closed circles) of bumetanide $(10 \mu M$ panel $A ; 100 \mu M$ panel $B)$. Each point is the mean (SE) of 10 experiments. Ach-acetylcholine.

acetylcholine. The contractions were $37 \cdot 6$ $(7 \cdot 2) \%$ in control rings and $41 \cdot 5(7 \cdot 1) \%$ in frusemide treated rings $(\mathrm{n}=6, \mathrm{NS})$. Frusemide pretreatment $(100 \mu \mathrm{M}$, contact time 30 minutes) did not alter the response to $1 \mathrm{nM}$ neurokinin $\mathrm{A}$. The contractions were $17 \cdot 7(2 \cdot 4) \%$ in control rings and $20.9(1.6) \%$ in frusemide treated rings $(n=6, N S)$.

Electrical field stimulation

Bumetanide $(10 \mu \mathrm{M})$ caused a significant inhibition of non-cholinergic, non-adrenergic contraction induced by electrical field stimula-

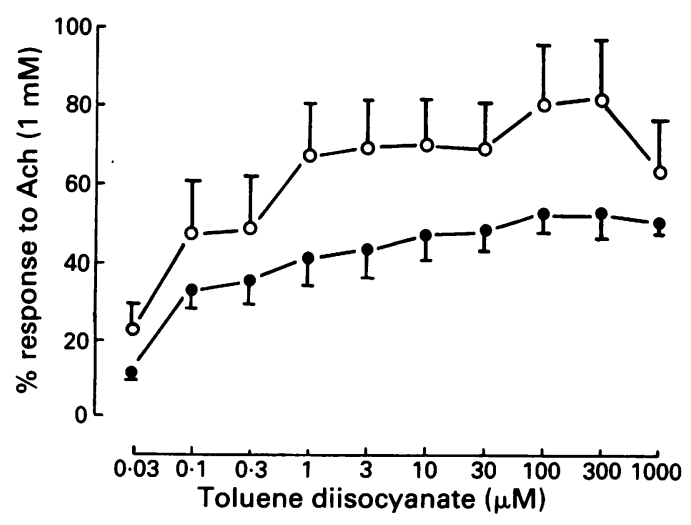

Figure 3 Effect of toluene diisocyanate on guinea pig main bronchi in the absence (open circles) and presence (closed circles) of frusemide (100 $\mu \mathrm{M})$. Each point is the mean (SE) of 10 experiments. Ach-acetylcholine. 
Results of analysis of variance ( $A N O V A$ ) with repeated measures

\begin{tabular}{llll}
\hline Drug & Preparation & $F$ Value & $p$ \\
\hline Bumetanide $(10 \mu \mathrm{M})$ & $\begin{array}{l}\text { Isolated guinea pig bronchi with the } \\
\text { epithelium intact } \\
\text { Isolated guinea pig bronchi with the } \\
\text { epithelium intact }\end{array}$ & 0.03 & $\mathrm{NS}$ \\
Bumetanide $(100 \mu \mathrm{M})$ & 0.52 & $\mathrm{NS}$ \\
Bumetanide $(10 \mu \mathrm{M})$ & $\begin{array}{l}\text { Isolated guinea pig bronchi with the } \\
\text { epithelium removed }\end{array}$ & 0.19 & $\mathrm{NS}$ \\
Bumetanide $(100 \mu \mathrm{M})$ & $\begin{array}{l}\text { Isolated guinea pig bronchi with the } \\
\text { epithelium removed } \\
\text { Isolated guinea pig bronchi with the } \\
\text { epithelium intact }\end{array}$ & 0.16 & $\mathrm{NS}$ \\
Frusemide $(100 \mu \mathrm{M})$ & & 1.48 & $\mathrm{NS}$ \\
\hline
\end{tabular}

tion. Under control conditions, field stimulation of the bronchial rings caused $9(2) \%, 15$ (3) $\%$, and $47(6) \%$ of maximum contraction respectively at 2,5 , and $10 \mathrm{~Hz}$. Bumetanide $(10 \mu \mathrm{M})$ caused an $89 \%$ inhibition of the response at $2 \mathrm{~Hz}(\mathrm{p}<0.01), 75 \%$ inhibition at $5 \mathrm{~Hz}(\mathrm{p}<0.01)$, and $38 \%$ inhibition at $10 \mathrm{~Hz}$ $(\mathrm{p}<0.05)$ (fig 4$)$. The vehicle for bumetanide had no significant effect on the response to field stimulation in bronchial smooth muscle rings. After pretreatment with ethanol, contractions were $8(2) \%, 14.5(3) \%$, and $46(8) \%$ of maximum contraction at 2,5 , and $10 \mathrm{~Hz}$ and these values did not differ from those obtained in control conditions.

\section{Discussion}

In the present study neither bumetanide ( 10 and $100 \mu \mathrm{M})$ nor frusemide $(100 \mu \mathrm{M})$ had a significant effect on the contractile response produced by toluene diisocyanate in guinea pig airways. It is possible that the lack of a significant change after frusemide treatment was due to the variability of the response. At a concentration $(10 \mu \mathrm{M})$ that has been shown to inhibit $\mathrm{Na} / \mathrm{K} / \mathrm{Cl}$ cotransport bumetanide inhibited the neurally mediated airways smooth muscle contraction induced by electrical field stimulation. Because bumetanide had no significant effect on the contractile response to exogenous acetylcholine or neurokinin A, our findings suggest that its effect on electrical field stimulation is due to an effect on airway nerves rather than a direct effect on contractility of airway smooth muscle. Previous work supports this conclusion. Frusemide in bovine airways

\footnotetext{
Figure 4 Effect of bumetadine $(10 \mu \mathrm{M})$ on the non-cholinergic response (atropine

$(1 \mu M)$ in the bath) to electrical field stimulation $160 \mathrm{~V}, 0.5 \mathrm{~ms}$ pulse width, 10 s train duration) in guinea pig isolated bronchi with the epithelium removed. Results are mean ( $S E)(n=4)$ ${ }^{\star} p<0.05 ;{ }^{\star \star} p<0.01$.
}

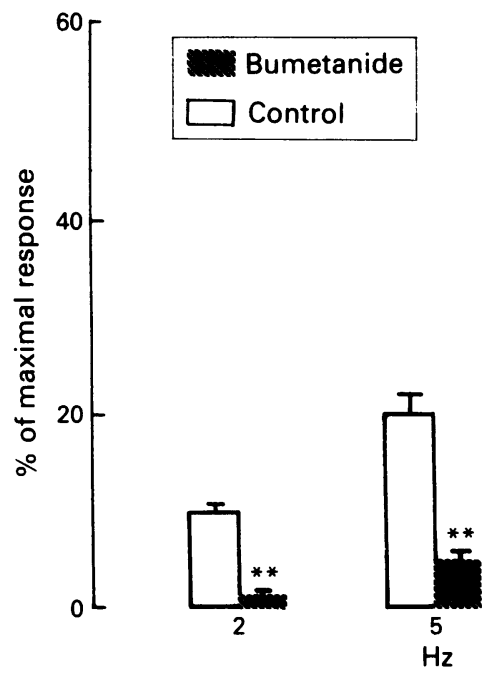

without epithelium failed to inhibit contraction induced by exogenous histamine, potassium chloride, or hyperosmolar saline, and was also without effect on hypertonic saline induced contraction in bovine and human airways with epithelium intact. The conclusions from this study, by Knox and Ajao, ${ }^{22}$ were that inhibition of $\mathrm{Na} / \mathrm{K} / \mathrm{Cl}$ cotransport does not alter airway smooth muscle contractility and that the protective effect of frusemide on bronchoconstrictor stimuli in vivo is unlikely to be due to a direct effect on airway smooth muscle. We found a similar lack of response with bumetanide on contractions induced by acetylcholine and neurokinin $\mathrm{A}$ on bronchial tissue with intact epithelium, so this would explain the lack of effect of loop diuretics in preparations with intact epithelium is not confined to one stimulus.

Inhaled frusemide has a protective effect on a wide range of bronchoconstrictor stimuli in vivo. It also inhibits cough induced by inhalation of solutions with low chloride content in humans but not that induced by capsaicin. ${ }^{23}$ The mechanism of action of frusemide on these different stimuli is not understood. Our results and the findings of previous studies suggest that, in human, bovine, and guinea pig airways at least, loop diuretics at concentrations that inhibit $\mathrm{Na} / \mathrm{K} / \mathrm{Cl}$ cotransport do not alter airway smooth muscle contractility.

Bumetanide inhibited contraction induced by electrical field stimulation. Electrical field stimulation in isolated bronchi of guinea pigs produces a reproducible constrictor response that is thought to be due to antidromic activation of capsaicin sensitive nerves, the response being largely mediated by endogenous tachykinin like peptides. ${ }^{24-27}$ Previous work has shown that bumetanide and frusemide inhibit both cholinergic and non-cholinergic excitatory nerves in guinea pig airways in vitro ${ }^{17}$ and one possible mechanism of action of these diuretics could be inhibition of the $\mathrm{Na} / \mathrm{K} / \mathrm{Cl}$ cotransport protein in airway nerves.

In the guinea pig isolated bronchus, frusemide and bumetanide have recently been shown to inhibit non-cholinergic, capsaicin sensitive bronchial contraction produced by electrical field stimulation without affecting the response to substance $P$, thus suggesting a prejunctional inhibitory effect. ${ }^{28}$ Our findings support this conclusion and they also suggest that prejunctional inhibition of tachykinin release by bumetanide does not involve mediator release from airway epithelium or generation of cyclooxygenase products as the inhibitory effect was evident in epithelium deprived bronchi and in the presence of indomethacin. Two other points emerge from our study in relation to the data of Elwood et $a l .{ }^{28}$ Firstly, the lack of effect of bumetanide on neurokinin $\mathrm{A}$ induced contraction suggests that neurokinin $A$ is acting at the postjunctional level. This is important because neurokinin A rather than substance $P$ is the main mediator of the tachykininergic response in guinea pig bronchi. ${ }^{29} 30$ Secondly, bumetanide inhibition of the non-cholinergic contraction was inversely related to the frequency of stimulation. 
This pattern would be expected from a substance that inhibited transmitter release at the prejunctional level.

The present study showed no significant inhibition of toluene diisocyanate induced contractions in guinea pig airways by bumetanide or frusemide. We have previously shown that toluene diisocyanate activates the sensory nerves in guinea pig airways by releasing tachykinins and that neutral endopeptidase may play a part in modulating the response. ${ }^{18}$ We have also shown that the action of toluene diisocyanate on sensory nerves is likely to be indirect, and that toluene diisocyanate may cause the generation of a prostanoid that in turn activates capsaicin sensitive primary afferents via a ruthenium red sensitive mechanism. ${ }^{20}{ }^{31}$ It was proposed recently that stimuli such as toluene diisocyanate or an increase in $\left[\mathrm{H}^{+}\right]$can release an endogenous capsaicin like substance that acts either on the capsaicin/ resiniferatoxin receptor or at a distinct receptor that shares a common membrane transduction mechanism/ion channel with the capsaicin/ resinferatoxin receptor. ${ }^{32}$

At least two independent modes of transmitter secretion are known to exist in peripheral terminals of capsaicin sensitive primary afferents. The first is activated by capsaicin and involves a calcium dependent transmitter secreted directly from the sensory nerve terminals; the second is activated by electrical field stimulation and involves a propagated action potential that invades the sensory nerve terminal with consequent depolarisation. ${ }^{27}$ The lack of effect of bumetanide and frusemide on toluene diisocyanate induced contraction at concentrations that inhibit electrical field stimulation induced contraction supports the existence of at least two distinct modes of transmitter release in peripheral terminals of capsaicin sensitive primary afferent nerves.

We are grateful to Luigi Zedda for drawing the figures and to $\mathrm{Dr}$ Licia Tolin for typing and editing the manuscript.

This work was supported in part by grants from the National This work was supported in part by grants from the National
Research Council (89.02961.04, 89.02664.04, FATMA 90.01508.CT04), the Italian Ministry of Education, Regione Veneto, the European Community of Coal and Steel, and the CNR-ENEL Project Interactions of Energy Systems with Human Health and Environment, Rome.

1 Cohen MR, Hirsch E, Vergona R, Ryan J, Kolis SJ, Schwartz A. Comparative diuretic and tissue distribution study of bumetanide and furosemide in the dog. J Pharmacol Exp Ther 1976;197:697-702.

2 Mudge GH, Weiner I. High-ceiling diuretics. In: Goodman Gilman A, Godman LS, Gilman A, eds. The pharmacological basis of therapeutics. New York: MacMillan, 1990;896-900

3 Bianco S, Pieroni MG, Refini M, Rottoli L, Sestini P. Protective effect of inhaled frusemide on allergen-induced early and late asthmatic reactions. $N$ Engl $J$ Med 1989;321:1069-73.

4 Bianco S, Vaghi A, Robuschi M, Pasargiklian M. Prevention of exercise-induced bronchoconstriction by inhaled frusemide. Lancet 1988;ii:252-5.

5 Robuschi M, Vaghi A, Gambaro G, Spagnotto S, Bianco S. Inhaled frusemide $(F)$ is highly effective in preventing ultrasonically nebulized water (UHN20) bronchoconstriction. Am Rev Respir Dis 1988;137:412 (abstract)

6 Vaghi A, Robuschi M, Berni F, Bianco S. Effect of inhaled frusemide $(F)$ on bronchial response to histamine $(\mathrm{H})$ in asthma. Eur Respir J 1988;1(suppl 2):4069 (abstract).
7 Nichol GM, Alton EWFW, Nix A, Geddes DM, Chung KF, Barnes PJ. Effect of inhaled frusemide on metabisulphite and methacholine induced bronchoconstriction and nasal potentials in asthmatic subjects. Thorax 1989;44:851P (abstract).

8 Bianco S, Pieroni MG, Refini M, Sturman A, Robuschi M. Inhaled frusemide $(F)$ prevents allergen induced bronchoconstriction in atopic asthmatics [abstract]. Am Rev choconstriction in atopic
Respir Dis 1988;137:27.

9 O'Connor BJ, Chung KF, Chen-Worsdell YM, Fuller RW, Barnes PJ. Effect of inhaled furosemide and bumetanide on adenosine 5'-monophosphate- and sodium metabilsulfiteinduced bronchoconstriction in asthmatic subjects. $\mathrm{Am}$ Rev Respir Dis 1991;143:1329-33.

10 Deth RC. Influence of frusemide on rubidium 86 uptake and alpha-adrenergic responsiveness of aterial smooth muscle. Blood Vessels 1987;24:321-33.

11 Widdicombe JH. Ion transport by tracheal cells in culture. Clin Chest Med 1986;7:299-305.

12 Welsh MJ. Inhibition of chloride secretion of frusemide in canine tracheal epithelium. J Membr Biol 1983;71: 219-26.

13 Lloyd EL. Frusemide and prevention of bumetanide. Lancet 1988;2:564 (letter).

14 Belcher NG, Rees PJ, Clark TJH, Lee TH. A comparison of the refractory periods induced by hypertonic airway challenge and exercise in bronchial asthma. Am Rev Respir Dis 1987;135:822-5.

15 Hook WA, Siraganian RP. Influence of anions, cations, and osmolarity on anti-IgE induced histamine release from human basophils. Immunology 1981;3:723-31.

16 Barnes PJ. Asthma as an axon reflex. Lancet 1986;1:242-5.

17 Elwood W, Lotvall JO, Barnes PJ, Chung KF. Loop diuretics inhibit cholinergic and noncholinergic nerves in guinea pig airways. Am Rev Respir Dis 1991;143:1340-4.

18 Mapp CE, Boschetto P, Dal Vecchio L, Maestrelli P, Fabbri LM. Occupational asthma due to isocyanates. Eur Respir J 1988;1:273-9.

19 Mapp CE, Chitano P, Fabbri LM, Patacchini R, Santicioli P, Geppetti P, Maggi CA. Evidence that toluene diisocyanate activates the efferent function of capsaicinsensitive primary afferents. Eur $J$ Pharmaco 1990;180:113-8.

20 Mapp CE, Chitano P, Fabbri LM, Patacchini R, Maggi CA. Pharmacological modulation of the contractile response to toluene diisocyanate in the rat isolated urinary bladder. Br J Pharmacol 1990;100:886-8.

21 Mapp CE, Graf PD, Boniotti A, Nadel JA. Toluene diisocyanate contracts guinea pig bronchial smooth muscle by activating capsaicin-sensitive sensory nerves. $J$ Pharmacol Exp Ther 1991;256:1082-5.

22 Knox AJ, Ajao P. Effect of frusemide on airway smooth muscle contractility in vitro. Thorax 1990;45:856-9.

23 Ventresca PG, Nichol GM, Barbes PJ, Chung KF. Inhaled frusemide inhibits cough induced by low chloride content solutions but not by capsaicin. Am Rev Respir Dis 1990;142:143-6.

24 Szolcsanyi J, Bartho L. Capsaicin-sensitive non-cholinergic excitatory innervation of the guinea-pig tracheobronchial smooth muscle. Neurosci Lett 1982;34:247-50.

25 Bartho L, Amann R, Saria S, Szolcsanyi J, Lembeck F Peripheral effect of opioid drugs on capsaicin-sensitive neurones of the guinea-pig bronchus and rabbit ear. Naunyn-Schmiedebergs Arch Pharmacol 1987;336:316-21.

26 Lundberg JM, Saria A, Brodin E, Rosell S, Folkers K. A substance $P$ antagonist inhibits vagally-mediated increase in vascular permeability and bronchial smooth muscle contraction in the guinea-pig. Proc Natl Acad Sci USA 1983;80:1120-3.

27 Maggi CA, Patacchini R, Giuliani S, Santicioli P, Meli A. Evidence for two independent modes of activation of the "efferent" function of capsaicin-sensitive nerves. Eur $J$ "efferent" function of capsa

28 Elwood W, Barnes PJ, Chung KF. Inhibition of neurally mediated contraction of guinea-pig airway smooth muscle by frusemide and bumetanide in vitro. $\mathrm{Br} J$ Pharmacol 1990;100:473P.

29 Maggi CA, Patacchini R, Baroldi P, Theodorsson E, Meli A Immunoblockade by a specific tachykinin antiserum of the non-cholinergic contractile responses in the guinea-pig isolated bronchus. J Auton Pharmacol 1990;10:173-9.

30 Maggi CA, Patacchini R, Rovero P, Santicioli P. Tachykinin receptors and noncholinergic bronchoconstriction in the guinea-pig isolated bronchi. AmRev Respir Dis 1991;144:363-7.

31 Mapp CE, Graf PD, Boniotti A, Nadel JA. Bronchial smooth muscle responses evoked by toluene diisocyanate are inhibited by ruthenium red and by indomethacin. Eur J Pharmacol 1991;200:73-6.

32 Maggi CA. Capsaicin and primary afferents neurones: from basic science to human therapy? J Auton Pharmacol 1991;11:177-212. 